\title{
Medo, infodemia e desinformação: a timeline dos discursos sobre coronavírus nas redes sociais
}

\author{
Fear, infodemic and desinformation: the \\ discursive timeline about coronavirus on social networks
}
Miedo, infodemia y desinformación: la línea de tiempo de los discursos sobre el coronavirus en las redes sociales

\author{
Fábio Malini ${ }^{1}$ \\ Universidade Federal do Espírito Santo \\ Camilla Reisler Cavalcanti ${ }^{2}$ \\ Universidade Federal do Espírito Santo
}

Ana Paula Miranda Costa Bergami ${ }^{3}$

Universidade Federal do Espírito Santo

Ligia Iunes Venturott ${ }^{4}$

Universidade Federal do Espírito Santo

Marcela Tessarolo Bastos ${ }^{5}$

Universidade Federal do Espírito Santo

\footnotetext{
1. Professor Associado II no Departamento de Comunicação Social da Universidade Federal do Espírito Santo (UFES). Doutor em Comunicação pela Universidade Federal do Rio de Janeiro (UFRJ), com pós-doutorado no Kings College London, no Reino Unido. Coordenador do Laboratório de Estudos sobre Imagem e Cibercultura (Labic) da UFES. E-mail: fabiomalini@gmail.com.

2. Doutoranda em Estudos Linguísticos pela UFES, com bolsa CAPES. Pesquisadora do Labic. E-mail: camillitz@hotmail.com.

3. Doutoranda em Estudos Linguísticos pela UFES, com bolsa FAPES. Pesquisadora do Labic. E-mail: ana.m.costa@edu.ufes.br.

4. Mestranda em Engenharia Elétrica pela UFES. Pesquisadora do Labic. E-mail: ligia.venturott@gmail.com.

5. Doutoranda em Comunicação pela Universidade Federal de Minas Gerais (UFMG). Pesquisadora do Labic. Professora da Universidade Vila Velha (UVV). E-mail: marcela.tessarolo@gmail.com.
} 
Resumo: O presente artigo mapeia e analisa as primeiras narrativas sobre o surgimento do novo coronavírus elaboradas em português e inglês no Twitter. Para isso, coletamos por meio de big data, as mensagens contendo a palavra coronavírus, em três datas: 14, 21 e 28 de janeiro de 2020. Recorrendo à mineração dos dados, processamos 122.026 postagens em português e 934.095 em inglês. Observamos que, já no início da pandemia, há um predomínio de um vocabulário epidemiológico que expressa os sentimentos de alerta, preocupação e raiva acerca dos contágios que se iniciam em Wuhan, na China, e, ainda em janeiro, se espalha pela Ásia, Europa e Estados Unidos. A partir dessa metodologia que cartografa as narrativas na cronologia das redes (que denominados de timeline discursiva), concluímos que viver o medo do desconhecido é a base emocional comum que pauta o comportamento de quem se dirige às redes sociais em busca de (des)informação e conversação nas redes quanto às características e aos impactos da pandemia.

Palavras-chave: Narrativas. Análise de Redes Sociais. Desinformação6 ${ }^{6}$ Covid-19. Infodemia.

Abstract: This article maps and analyzes the first narratives about the emergence of the new coronavirus elaborated in Portuguese and English on Twitter. For this, we collected through big data, the messages containing the word coronavirus, on three dates: January 14, 21 and 28, 2020. Using data mining, we processed 122,026 posts in Portuguese and 934,095 in English. We observed that already at the beginning of the pandemic, there is a predominance of an epidemiological vocabulary that expresses feelings of alertness, concern and anger about the contagions that started in Wuhan,

6. Chamamos a atenção para o fato de que 'desinformação' pode ter duas traduç̃̃es em inglês: 1. Misinformation - informação errada ou o fato de pessoas estarem mal-informadas (com ruídos, etc.) 2. Disinformation - informação propositalmente falsa, normalmente espaIhada de forma velada, para camuflar a verdade. Alertamos ainda que os dois termos já começam a ser usados de forma intercambiável. 
China. Still in January, these spread across Asia, Europe and the United States. From this methodology that maps the narratives in the chronology of the networks (which we name discursive timeli$n e)$, we conclude that living the fear of the unknown is the shared emotional basis that guides the behavior of those who turn to social networks in search of (dis)information and conversation about the pandemic.

Key words: Narratives. Social Network Analysis Mis/Disinformation. Covid-19.

Resumen: Este artículo mapea y analiza las primeras narrativas sobre la aparición del nuevo coronavirus elaboradas en portugués e inglés en Twitter. Para ello, recolectamos a través de big data, los mensajes que contienen la palabra coronavirus, en tres fechas: 14, 21 y 28 de enero de 2020. Mediante minería de datos, procesamos 122.026 publicaciones en portugués y 934.095 en inglés. Observamos que, ya en el inicio de la pandemia, predomina un vocabulario epidemiológico que expresa sentimientos de alerta, preocupación e ira por los contagios que se inician en Wuhan, China, e incluso en enero, se extiende por Asia, Europa y Estados Unidos. A partir de esta metodología que mapea las narrativas en la cronología de las redes (que se denominan timeline discursiva), concluimos que vivir el miedo a lo desconocido es la base emocional común que guía el comportamiento de quienes acuden a las redes sociales en busca de (des) información y conversación en las redes sobre las características e impactos de la pandemia.

Palabras clave: Narrativas. Análisis de Redes Sociales. Desinformación. Covid-19.

Data de submissão: 11/11/2020

Data de aprovação: 16/12/2020 
Medo, infodemia e desinformação: a timeline dos discursos sobre coronavírus... Fábio Malini • Camilla Reisler Cavalcanti, et al...

\section{Introdução}

As narrativas nas plataformas de mídias sociais sobre a pandemia de Covid-19 vão configurar as disputas entre lideranças políticas, evidenciar os posicionamentos de grandes conglomerados empresariais, ressaltar os sentimentos da audiência conectada e até moldar as políticas públicas no Brasil. Este artigo tem o objetivo de mapear e analisar como surgem elementos biográficos próprios do começo da pandemia da Covid-19 no Twitter, em português e inglês, por meio de uma comparação do léxico e dos sentimentos em três datas: 14, 21 e 28 de janeiro de 2020. Nossa hipótese é que a desinformação sobre a pandemia se relaciona com a incerteza informacional. E para testá-la, partimos da constatação de que as narrativas construídas nas plataformas digitais orientam e moldam comportamentos tanto individuais quanto coletivos. É, portanto, analisando as variações discursivas no tempo é que se é possível cravar os diferentes enquadramentos temáticos que oscilam nas opiniões e conversações públicas das redes sociais. A captura dessa variação, através da identificação de redes de palavras interconectadas, por dia, é o que denominamos de timeline discursiva nesse estudo.

O caso da Covid-19 ilustra a relevância em se estudar a narrativa como condutora de sentidos por emoldurar diferentes atitudes expressas quanto ao evitar a propagação do vírus, ao tratar a doença e ao se prevenir dela. Em nosso trabalho registramos as narrativas que marcam a genealogia do discurso sobre a doença, tendo um papel fundamental na linguagem adotada durante toda a pandemia: a narrativa do medo advindo do mistério e a narrativa da urgência levando à desinformação. 
Medo, infodemia e desinformação: a timeline dos discursos sobre coronavírus... Fábio Malini • Camilla Reisler Cavalcanti, et al...

\section{Metodologia}

No rastro dessa timeline discursiva gerada pelo coronavírus no Twitter, coletamos mensagens contendo a palavra "coronavírus" (visto que este era o único termo assertivo sobre a Covid-19), nos dias 14, 21 e 28 de janeiro de 2020, em português e inglês. $O$ período é marcado pela confirmação do nexo entre o coronavírus e o surto de pneumonia severa de origem misteriosa que ocorreu em Wuhan, na China, assim como o registro do primeiro caso nos Estados Unidos. Ao total, foram analisadas 122.026 postagens em português e 934.095 em inglês.

Feita a genealogia das narrativas da pandemia, exploramos a metodologia e os resultados obtidos a partir da aplicação desses nossos conceitos de timeline discursiva e redes de narrativas, úteis para analisar, dia a dia, os léxicos que hegemonizaram o discurso factual sobre a doença.

A extração dessas postagens foi feita com o script Ford, tecnologia de extração e mineração de dados desenvolvida pelo Labic-Ufes ${ }^{7}$, que coleta dados diretamente do API do Twitter e disponibiliza o dataset ${ }^{8}$ completo com os dados para download, em formato de planilhas. Após coletar todos os atores, o Ford libera arquivos em formato .gdf e permite a análise e visualização dos dados extraídos a partir do aplicativo de código aberto Gephi ${ }^{9}$ (com o uso do algoritmo de layout Force Atlas 2), usado para a produção dos grafos que ilustram o artigo.

Para a rede de narrativas, foram identificadas as 100 palavras mais frequentes nas mensagens, funcionando como os nós (pontos) da rede. E, em seguida, as 10 palavras mais associadas a

7. Laboratório de Estudos sobre Imagem e Cibercultura - http://www.labic.net/

8. O termo dataset refere-se a "um conjunto de dados que consiste em uma série de registros tabulados (em formato de tabelas). Cada coluna representa uma variável particular e cada linha corresponde a um determinado elemento do conjunto de dados em questão" (CANCIAN E MALINI, 2017, p. 10).

9. Cf. http://gephi.org. Acesso em 25 out.2020. 
Medo, infodemia e desinformação: a timeline dos discursos sobre coronavírus... Fábio Malini • Camilla Reisler Cavalcanti, et al...

cada uma dessas 100. A teia de conexões entre todas as palavras associadas é visualizada através de um grafo (representação matemática de relações entre entidades), formado por nós (palavras) e arestas (o número de vezes que as palavras aparecem juntas nas mensagens). Nas arestas, há um peso lexical, que, no grafo, é representado pela largura das linhas entre elas. Assim, quanto mais espessa a linha, mais intensa é a relação de uma palavra com a outra. Quanto maior é o tamanho da palavra, mais vezes ela foi mencionada nos posts.

Para cada dia analisado, há uma rede de palavras (narrative network), que colocada de modo cronológico, forma uma timeline discursiva, cujo efeito analítico final é o de estabelecer uma rede temporal de narrativa, demonstrando as mudanças de vocábulos, as disputas de sentidos e a popularidade de termos no tempo analisado, ou seja, nas três primeiras semanas após a confirmação do surto em Wuhan.

Apoiamo-nos ainda no Emolex (Mohammad e Turney, 2013), para a análise de sentimentos sobre os dados, que constitui uma grande base de dados de termos em inglês associados a emoções genéricas, construída por meio de anotações manuais. Foram abordados os sentimentos: alegria, tristeza, raiva, medo, confiança, desgosto, surpresa e antecipação que, para Plutchik (1980) seriam as emoções básicas do ser humano. Para a análise dos textos em português o dicionário Emolex foi traduzido para o português utilizando tradução automática.

Os textos passaram por um pré-processamento onde foram removidas as chamadas stopwords, palavras consideradas irrelevantes como artigos, conjunções, pronomes, e preposições. Inferimos o sentimento predominante contido em cada texto após a lematização das palavras restantes.

O uso de algoritmo classificador de sentimento serviu para correlacionar as emoções constituintes das mensagens que mol- 
Medo, infodemia e desinformação: a timeline dos discursos sobre coronavírus... Fábio Malini • Camilla Reisler Cavalcanti, et al...

dam a timeline discursiva, servindo assim para testagem se há ou não correlação da (des)informação com os aspectos mais emocionais nas trocas conversacionais sobre a pandemia de Covid-19.

\section{A origem de uma narrativa em rede}

A palavra narrativa é um linguajar comum entre os usuários das redes sociais. Virou um termo nativo desse ambiente. É o berço do narrativismo, o ato de construir experiências on-line que, ao ganharem impulso, abafam a individualidade em um sonambulismo coletivo. Da mesma forma surge a "contranarrativa" para "emplacar" o contrafluxo. Em outras palavras, a tentativa de fazer com que os usuários da rede "embarquem" nela e alimentem o ponto de vista, "abraçando" uma certa visão sobre um determinado acontecimento. Do contrário, pode-se até "montar" uma ótima narrativa, mas ela não vai "colar". É porque uma narrativa, para ser eficiente, não pode ser "forçada", visto que há coisas que não se "encaixam" na narrativa. Isso ocorre quando os atores, longe da verdade factual, "insistem" numa narrativa, fazendo tudo para "caber" qualquer coisa dentro dela, daí ela pode "sair pelo ralo". Uma narrativa precisa ser "sustentada" para ter uma chancela confiável. Deve se basear na realidade porque, assim, vai conseguir desviar o foco para aquilo que, para si, é mais relevante. Esse é o percurso para se "ganhar" a narrativa. Isto é, vencer a "guerra de narrativas", quando até seus adversários "alimentam-na".

A natureza efêmera das redes cria a necessidade de constante validação dos tópicos, orquestrada pelos narrativistas para que ela, a narrativa, não se canse, não seja "desmontada", "aglutinada" ou até "quebrada" nas conversações. Caso isso aconteça, é o "fim" da narrativa. Para ser mais preciso, o fim não é o en- 
Medo, infodemia e desinformação: a timeline dos discursos sobre coronavírus... Fábio Malini • Camilla Reisler Cavalcanti, et al...

cerramento da história, mas a saturação de "performá-la". Por isso, para aqueles que buscam a manutenção de uma ideologia hegemônica, o indicado é "corrigir" ou "mudar" a narrativa, "recuperar o controle" dela, transformando o sentido compartilhado em uma narração conveniente.

As palavras entre aspas, acima, foram usadas em tuítes junto do termo "narrativa". As reproduzimos para demonstrar como o termo se tornou popular nas mídias sociais digitais e passou a ser usado no cotidiano, em diferentes espaços, e em falas de políticos, empresários, militantes, entre outros.

Narrativas são fragmentos em circulação, são fenômenos complexos que, de acordo com Leal (2006), ao emergirem da inter-relação das forças sociais mais diversas, são equacionados para resultarem em pontos peculiares do fluxo histórico e social. Conseguem se repetir e, ao mesmo tempo, se diferenciarem porque são abertas, em fluxo, se dão nas interfaces e no tensionamento entre diversas forças. Não são necessariamente mentiras que constroem uma narrativa. A forma discursiva pode apoiar-se em construções semânticas já existentes para reforçar estereótipos culturais. Da mesma forma, as narrativas apresentam-se como "espaço de tensão, em que convivem coerção, resistência, consonâncias e dissonâncias" (LEAL, 2006, p.26) na arena da representação positiva de um grupo em contraponto com a representação negativa do outro.

O correspondente analógico é recuperado em sua forma digital instaurando a arena para a "guerra de narrativas" nas redes sociais. Se antes a tensão era fabricada por especialistas em promover na imprensa versões favoráveis sobre um dado acontecimento para seus clientes, agora, a interface oferecida pelas plataformas digitais é orquestrada por influenciadores em canais de mídias sociais. É o que Seargeant (2020, p. 60) denomina de identidade narrativa, organizando as práticas sociais de seus inte- 
Medo, infodemia e desinformação: a timeline dos discursos sobre coronavírus... Fábio Malini • Camilla Reisler Cavalcanti, et al...

grantes. "Narrativas dão sentido ao mundo, põem coisas em seu lugar de acordo com nossa experiência, e então nos fala o que fazer. Elas são uma estrutura organizadora de nossos pensamentos" (SEARGEANT, 2020, p. 61, tradução nossa ${ }^{10}$ ).

A narrativa coloca a história acima de tudo e gera assim um grande risco. Descartar fatos em prol de uma narrativa revela as prioridades de um grupo assim como o preço que se está disposto a pagar. Negar ou afirmar para manter uma narrativa "viva" e condizente com ideologias apaga qualquer sinal de subjetividade. Assim, pessoas tornam-se apenas pano de fundo de um opaco cenário desumanizado.

Em redes sociais, a estrutura semântica da narrativa está alicerçada em um sistema lexical próprio, que se impregna com o passar do tempo, sendo reproduzida por um agrupamento de perfis. Este é um exército de exaltação a uma versão com a única função: a viralização (compartilhamentos, views e likes), para então buscar o domínio do fluxo das conversações e replicar aqueles que compartilham da mesma ótica.

A narração nas redes telemáticas é esta tessitura dos fios da vida social para um determinado empenho, cuja moral é a de manutenção do status quo. Já as contra narrativas nascem de um esforço de grupos marginalizados que buscam a ruptura de submissões estabelecidas por dinâmicas de poder que regem as plataformas digitais.

A narrativa não é só terreno fértil de fake news, mas sobretudo é a revelação de um sistema no qual pessoas são aparatos de enredo para uma narrativa "superior" e, por isso, são dispensáveis e consumíveis. Falsas histórias emulam uma narrativa, mas sem fatos verificados que as sustentem como algo crível (MURUN-

10. Narratives make sense of the world, put things in their place according to our experience, and then tell us what to do. They're an organizing framework for our thoughts. 
Medo, infodemia e desinformação: a timeline dos discursos sobre coronavírus... Fábio Malini • Camilla Reisler Cavalcanti, et al...

Gl et al, 2018). Uma vez construída e lançada, é um instrumento de reconstituição do acontecimento que abriga a crença de um coletivo, e por ser fundada em fatos verificáveis, assemelha-se a uma meia-verdade. Os léxicos que surgem na primeira data deste trabalho são pedras de toque para vários narradores exponencializados em rede. Por isso que não há narrador único; a timeline discursiva é explicitada de modo objetivo (como léxicos comuns) na variação dos discursos. A narrativa é a meia-verdade para o acontecimento, viralizada para robustecer o sistema de crenças de um coletivo em pleno poder.

A exemplo de outras epidemias e/ou doenças surgidas no mundo, como aponta Susan Sontag (1988), as narrativas e "metáforas" sobre a Covid-19 vão se formando, só que dessa vez nas plataformas de mídias sociais. A culpa pelo fato de a doença ser intratável, desconhecida e rodeada de mistérios e de medo, recai sobre as próprias vítimas. O caráter de uma pessoa torna-se a causa da doença é fenômeno que se estende às culturas. Metáforas, estereótipos e fantasias sentimentais acompanham enfermidades manifestando o léxico adjacente. A autora observa que não só "a doença não é uma metáfora", mas também que é quase impossível o doente não ter sido impactado pelo discurso que ronda as enfermidades (SONTAG, 1988, p. 6). Logo, o ideal é desmistificar enfermidades para tratá-las de maneira mais fidedigna e humanizada.

Entretanto, o medo é onipresente, uma vez que é inato ao ser humano e é a palavra que define a nossa incerteza diante ou não de um risco (BAUMAN, 2012). Dessa forma, o medo da morte é o mais humano, constante, universal e o princípio de todos os medos. É uma emoção que nos afeta negativamente, um instinto de sobrevivência causado pela ideia de um risco futuro. Esse sentimento provoca um desconforto, uma "dor imaginária" pelo receio do que pode ocorrer. Assim, o medo causa apreensão e ansiedade, e assus- 
Medo, infodemia e desinformação: a timeline dos discursos sobre coronavírus... Fábio Malini • Camilla Reisler Cavalcanti, et al...

ta porque é construído na incerteza (WOLFF, 2007). O surgimento da Covid-19 traz narrativas repletas de sentimentos de mistério, de medo e de associações culturais, que descrevemos a seguir.

\section{Timeline discursiva e a primeira narrativa: o dia 14 de janeiro}

Identificamos a cronologia lexical da Covid-19 ganhando forma dia a dia nas redes, para poder avaliar as principais narrativas que envolviam o tema - a do medo e a da urgência. O trabalho nos ajudou a reconhecer o principal efeito dessa cronologia, a saber: a coesão na linguagem de grupos ou temas dominantes. Com os atores em rede intercalando-se no entrar e sair do debate conectado, buscamos analisar as diferentes sobreposições temporais que um determinado acontecimento executa nas redes telemáticas, assim como a coesão da timeline discursiva ocorre ou se perde nesse tempo. Consideramos que uma maior duração dessa coesão representa uma tática primordial para formar a opinião de atores sociais dentro e fora da internet.

No início da pandemia, a imprensa tradicional e a Organização Mundial da Saúde (OMS) pautaram a temática das conversações em rede, sustentando a coesão lexical que evidenciava o mistério epidemiológico em torno da doença. A sintonia de vocabulário identificada no presente estudo alicerça a ideia de uma timeline discursiva, composta de grafo de palavras visualizadas, organizadas temporalmente, mostrando a lógica de um discurso por meio de um conjunto de termos que se repetem ao longo dos dias, fortalecendo a narrativa.

Quando o ano de 2020 se iniciava, sabia-se que vários pacientes com quadros similares ao da Síndrome Respiratória Aguda (SARS) e 
Medo, infodemia e desinformação: a timeline dos discursos sobre coronavírus... Fábio Malini • Camilla Reisler Cavalcanti, et al...

pneumonia severa haviam chegado a hospitais de Wuhan, na China. Porém, com pouco sucesso nos tratamentos e pouca divulgação de informações, a Covid-19 passou a ser chamada de "doença "misteriosa"11 $^{\prime 1}$ nas redes, termo adotado inicialmente pela imprensa profissional. Antes mesmo do fim de 2019, um universo vocabular do rumor

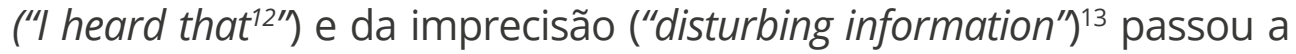
repertoriar as redes para tentar elucidar os casos em Wuhan, que então descartava que os doentes tinham SARS ou MERS ${ }^{14}$. Os canais comunicacionais adotaram narrativas do mistério para lidar com a imprecisão e atender à necessidade humana de buscar respostas para desvendar as causas e efeitos daquela pneumonia.
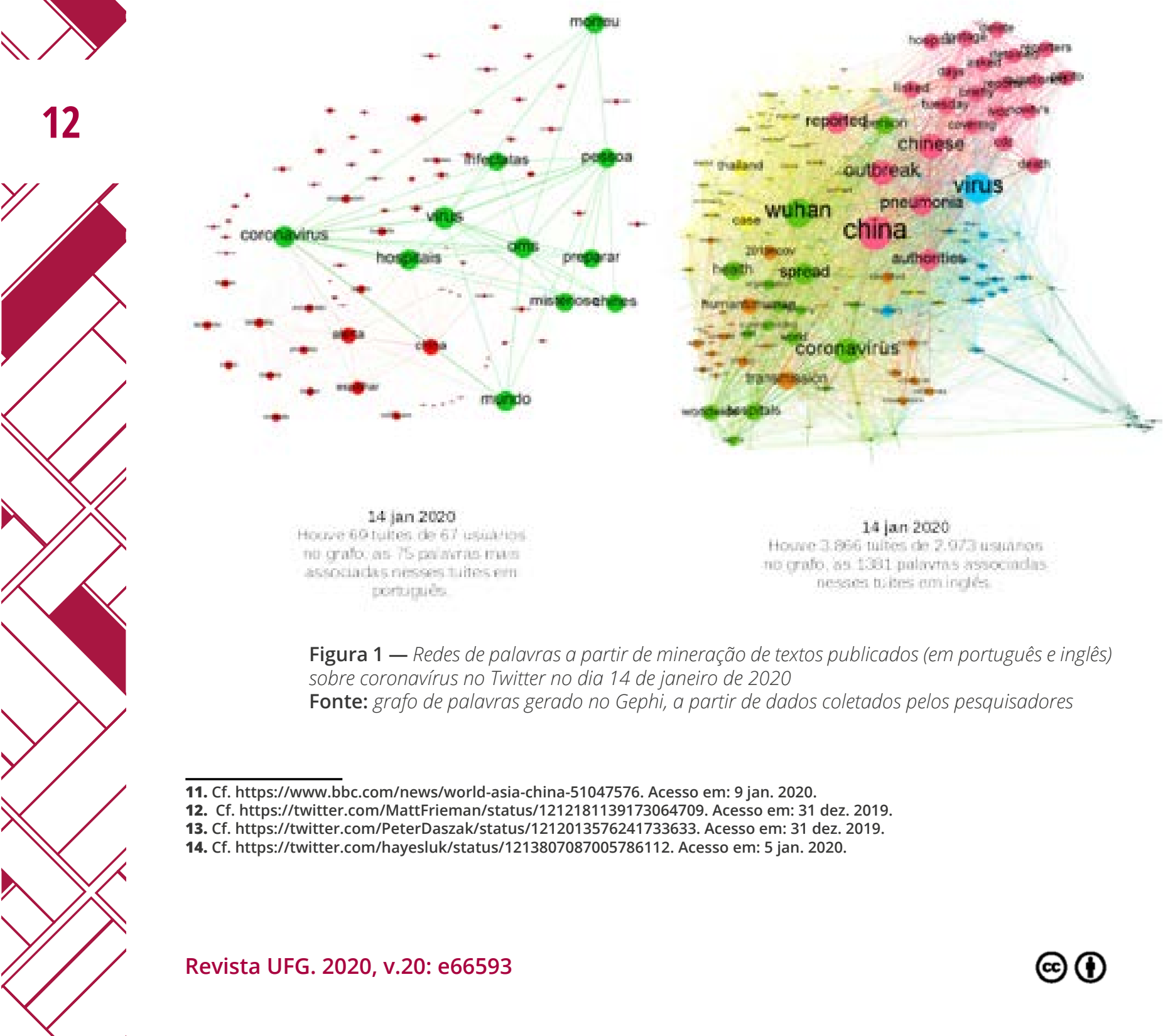

Figura 1 - Redes de palavras a partir de mineração de textos publicados (em português e inglês) sobre coronavírus no Twitter no dia 14 de janeiro de 2020

Fonte: grafo de palavras gerado no Gephi, a partir de dados coletados pelos pesquisadores

\footnotetext{
11. Cf. https://www.bbc.com/news/world-asia-china-51047576. Acesso em: 9 jan. 2020.

12. Cf. https://twitter.com/MattFrieman/status/1212181139173064709. Acesso em: 31 dez. 2019

13. Cf. https://twitter.com/PeterDaszak/status/1212013576241733633. Acesso em: 31 dez. 2019.

14. Cf. https://twitter.com/hayesluk/status/1213807087005786112. Acesso em: 5 jan. 2020.
} 
Medo, infodemia e desinformação: a timeline dos discursos sobre coronavírus... Fábio Malini • Camilla Reisler Cavalcanti, et al...

Identificamos que, no dia 14 de janeiro, o termo "coronavírus" está mais conectado a termos como "hospitais", "mundo", "OMS". Porém, no dia 21 de janeiro, a correlação é outra: "China", "surto", "confirmado". Podemos identificar que há uma diferença considerável na quantidade de menções aos termos, com maior diversidade de termos emergindo no dia 21, evidenciando que a maior presença de atores numa rede representa um maior volume de interações entre as palavras, visto que passam a ser empregadas para modelar diferentes histórias. Se o termo "hospitais" foi mencionado 36 vezes no dia 14, "China" registrou 1.569 citações no dia 21, o que aponta para a transição da ideia de localidade. Ou seja, inicialmente a visão se vira para o paciente e a doença, sendo o hospital central. Em seguida, verte-se para a população e a epidemia, sendo o território chinês o mais relevante

No rastro do termo "coronavírus" pelas redes sociais, iniciamos nosso caminho pelo dia 14 de janeiro de 2020. Acompanhando a disputa informacional gerada pelo termo "coronavírus", nossa busca genealógica rastreou a palavra e suas respectivas co-associações, em inglês e português. Os primeiros tuítes, nos dois idiomas, demonstraram que o vírus e a doença estavam inscritos em comentários e notícias associando-os ao desconhecido, novo ou misterioso, despertando o medo, como mostram as Tabelas 1 e 2 . Em inglês, a análise de sentimentos mostra o medo com 33,57\%, seguido da antecipação (24,64\%) e, em menor escala, a confiança (12,56\%), como demonstra a Tabela 1. Em português, o medo domina a análise de sentimentos, com $78,26 \%$, seguida da antecipação $(8,7 \%)$, como podemos observar na Tabela 2. Assim, a origem e o vírus em si ainda eram incógnitas, justificando a formação de um estado de alerta global, ainda que apenas compartilhado por uma pequena comunidade científica. 
Medo, infodemia e desinformação: a timeline dos discursos sobre coronavírus... Fábio Malini • Camilla Reisler Cavalcanti, et al...

Apesar de o grafo em português nos apresentar nada além de notícias banais, palavras em inglês, do grafo de 14 de janeiro de 2020, já demonstram o estado de "alerta" emitido tanto por autoridades quanto por jornalistas vinculados à China em 'aviso'('warn) ao mundo todo (presença de 'journalists', 'CDC' e 'authorities' no cluster rosa). Neste momento, há certa credibilidade nos emissores de informações, no fato de a doença poder ser transmitida entre humanos e de o vírus conter potencialmente fatores "superdisseminadores". No entanto, o cluster marrom nos mostra a investigação ainda incipiente de cientistas com a presença de termos como 'investigação', 'clara', 'evidência', 'conduziu' e 'preliminar'. Apesar da coleta em inglês, o espaço geográfico parece estar limitado à Ásia (Grafo amarelo), demonstrando forte correlação entre a Tailândia e a palavra 'casos' (cases em inglês). Neste mesmo cluster, percebe-se indagações a respeito da origem e forma de contágio da doença pela espessura das setas entre 'Tailândia', 'mercado', 'frutos do mar', 'paciente', 'visita' e 'importado'. Aqui surgem também as primeiras ações médicas que hoje sabemos que são léxicos definitivos da pandemia a saber: 'quarentena', 'hospitalizado', 'confirmado por laboratório', 'monitorado', 'diagnóstico', 'infectado', 'detectado' e 'onset'. Este último sendo traduzido habitualmente para início, começo, surgimento ou eclosão principalmente de doenças ou desencadeamento de crises.

No entanto, há uma primeira contenda quanto ao comportamento chinês divulgado pela CDC (autoridade americana presente no grafo rosa) com sede em Hong Kong. Os jornalistas de Hong Kong cobrindo o surto de pneumonia foram 'brevemente' ('briefly') 'detidos' ('detained') e 'questionados'('questioned') pelas autoridades chinesas, além de um outro repórter ter de apagar uma 
Medo, infodemia e desinformação: a timeline dos discursos sobre coronavírus... Fábio Malini • Camilla Reisler Cavalcanti, et al...

'filmagem' ('footage') do hospital. Essas atitudes reforçam o caráter enigmático do vírus assim como o modelo ocidental de que a China é um país fechado. Estava também na memória coletiva o fato de que o governo chinês manteve o surto em segredo durante o mês de dezembro. Na falta de informações, para sanar nossa inquietação, buscamos, por meio das nossas experiências e dos discursos, fazer inferências e pressuposições para que possamos guiar nosso comportamento. Esse início revela imensas lacunas, o que faz com que, para o leigo, não sobre outra alternativa a não ser apoiar-se em narrativas de filmes, da imprensa, do governo e das redes sociais.

\section{Sentimentos Predominantes no dia 14 - Inglês}

40

15

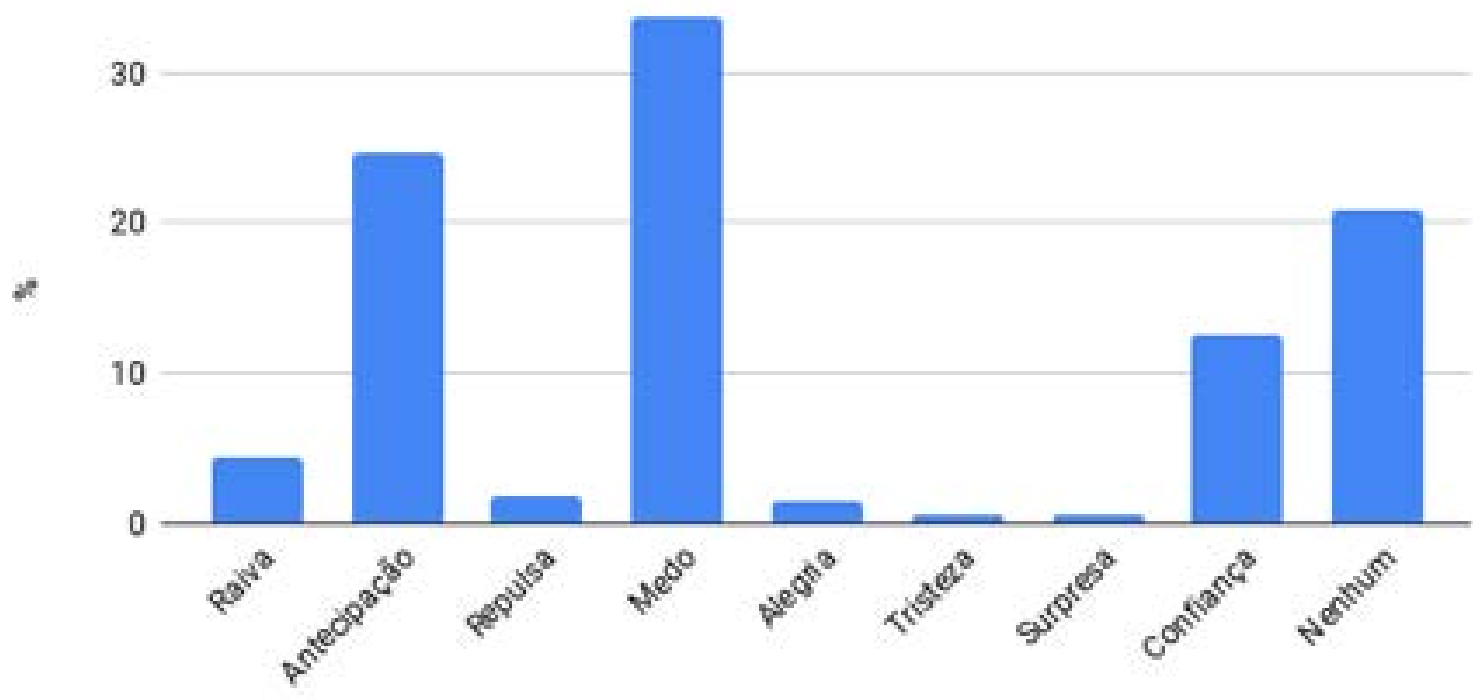

Tabela 1 - Análise de sentimentos preponderantes no Twitter, em inglês, no dia 14 de janeiro de 2020

Fonte: tabela produzida pelos autores, a partir de coleta de dados 
Medo, infodemia e desinformação: a timeline dos discursos sobre coronavírus... Fábio Malini • Camilla Reisler Cavalcanti, et al...

\section{Sentimentos Predominantes no dia 14 - Português}

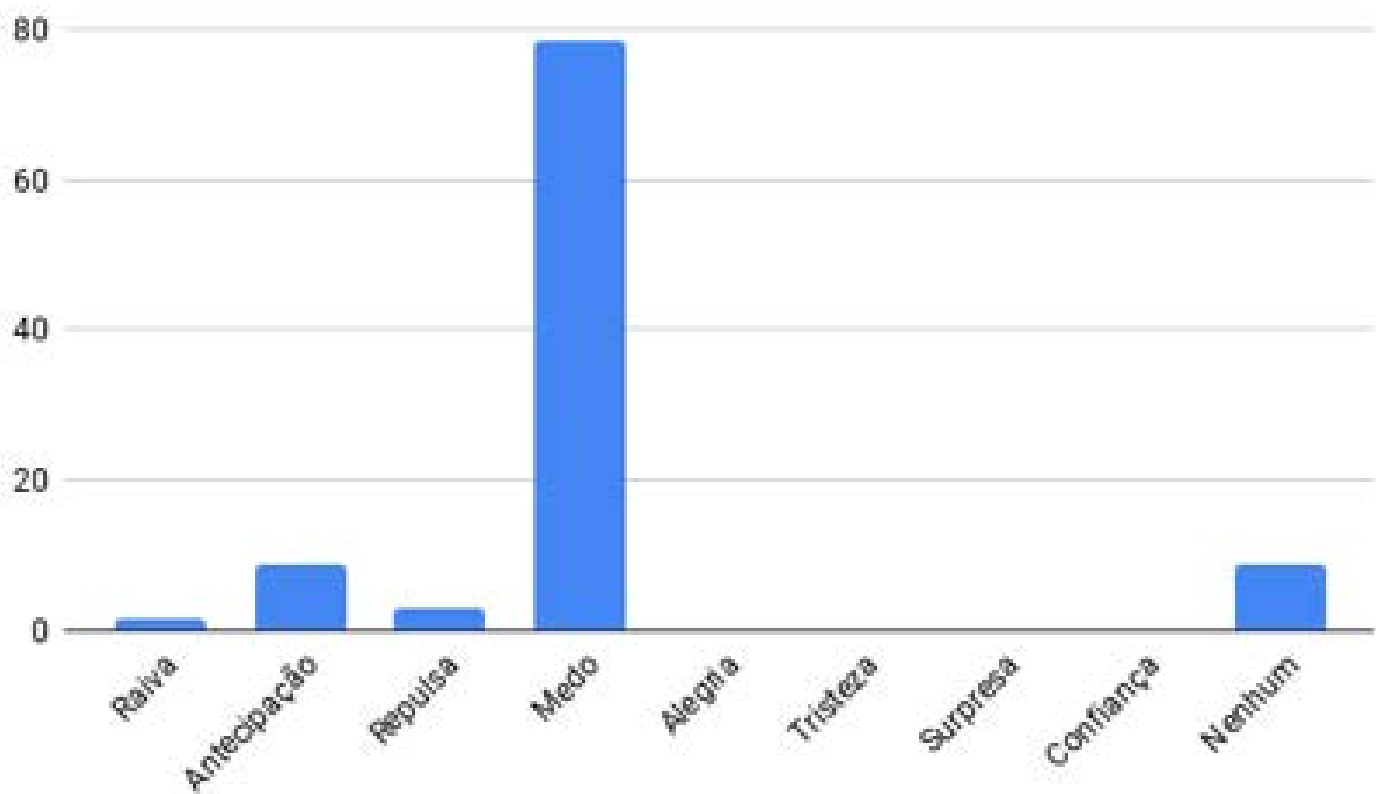

Tabela 2 - Análise de sentimentos preponderantes no Twitter, em português, no dia 14 de janeiro de 2020

Fonte: tabela produzida pelos autores, a partir de coleta de dados

\section{A segunda narrativa e a urgência pelas informações}

A partir do dia 21 de janeiro de 2020, o termo "coronavírus" passou a viralizar nas redes sociais, com uma propagação decorrente da confirmação, por parte das autoridades de saúde, do primeiro caso de Covid-19 nos Estados Unidos, em Seattle, no Estado de Washington. É o que constatamos ao analisar os dados na língua inglesa, representado na Figura 2 pelo cluster amarelo do grafo, com viés mais informacional. Daí a força das palavras 'coronavírus', 'wuhan' e 'china' associadas a 'confirmed', 'case', 'washington'15.

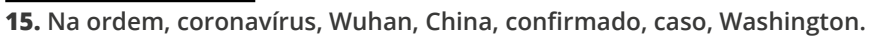


Medo, infodemia e desinformação: a timeline dos discursos sobre coronavírus... Fábio Malini • Camilla Reisler Cavalcanti, et al...

O cluster laranja se espraia pelo grafo acionando léxicos que acionam emoções, com associações de palavras como 'people', 'spread', 'virus', outbreak', 'countries', 'infected', 'airports', 'safe', 'horror', 'apocalyptic'16, denotando o medo do desconhecido por causa da propagação da doença ${ }^{17}$. Enquanto isso, o cluster azul traz as providências das autoridades de saúde, demonstrada por associação de palavras como 'health', 'emergency', 'committee', 'international'18, no dia em que a OMS informa a convocação de comitê de emergência para tratar o assunto ${ }^{19}$.

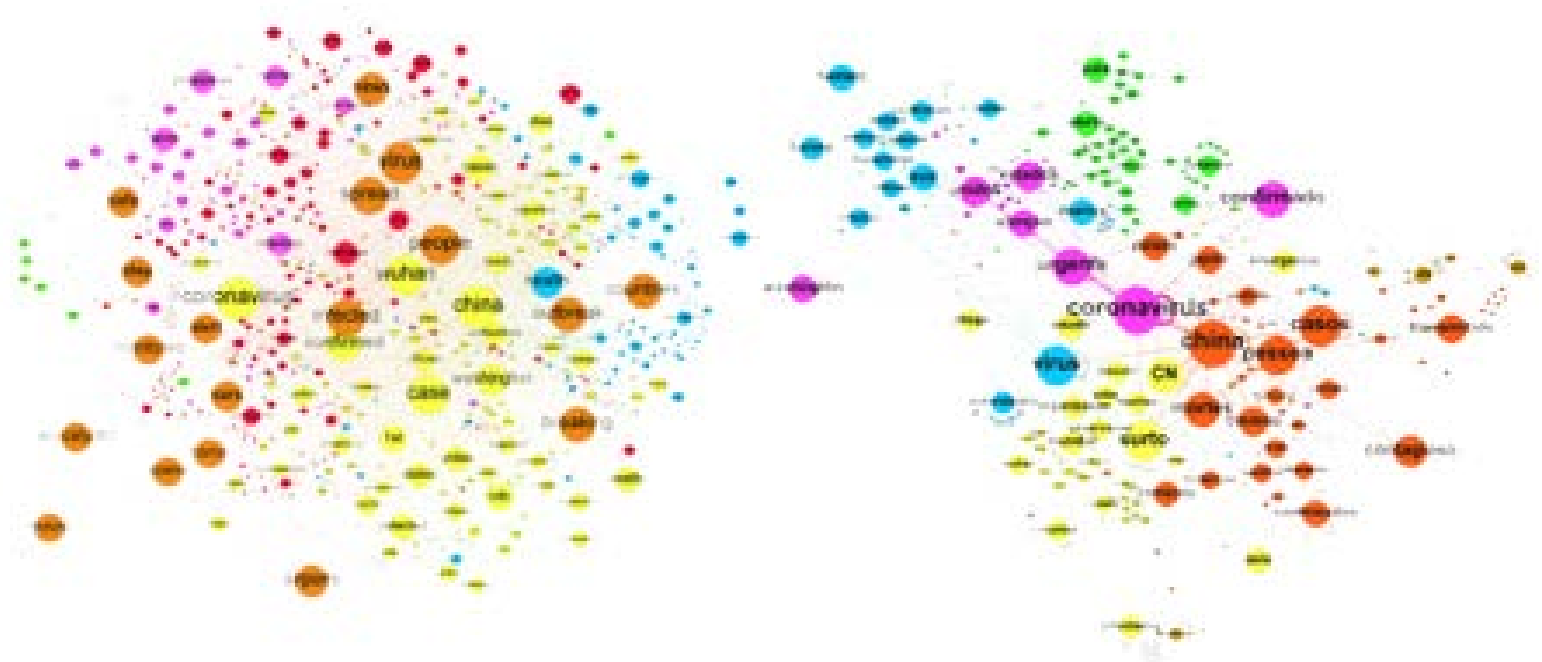

21 de janeiro de 2020

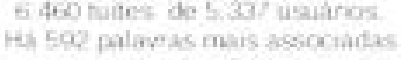
neyses thites

21 de jarvelio de 2020 196,659 butes de 109 . 821 esuános. ita 2170 poimuras mais ascocadst nessers alitet

Figura 2 - Redes de palavras a partir de mineração de textos publicados (em português e ing/ês) sobre coronavírus no Twitter no dia 21 de janeiro de 2020

Fonte: grafo produzido pelos autores, a partir de coleta de dados

No cluster roxo, evidencia-se a busca de informações de contágio da doença e, consequentemente, como se proteger, com

16. Na ordem, pessoas, disseminar, vírus, surto, países, infectado, aeroportos, segurança, horror, apocalíptico.

17. O tuíte mais retuitado do dia 21 de janeiro (11.512 vezes), em língua inglesa, é de conta suspensa e traz mensagem de alerta: "esta não é uma cena de filme de terror apocalíptico, mas o surto de \#coronavirus na China". Disponível em: https:// www.twitter.com/howroute/status/1219285703798022147. Um vídeo postado originalmente no mundo oriental o acompanha e mostra passageiros em um avião, tendo a temperatura medida por profissionais que usam EPI de segurança, inclusive máscaras. A cena, que passou a ser corriqueira no segundo semestre de 2020, causava estranheza e medo do contágio no início do ano. Disponível em: https://t.co/PIc7NYvsGO. Acesso em: 21 jan. 2020.

18. Na ordem, saúde, emergência, comitê, internacional.

19. Cf. https://twitter.com/WHO/status/1219317208205209600. Acesso em: 21 jan. 2020. 
Medo, infodemia e desinformação: a timeline dos discursos sobre coronavírus... Fábio Malini • Camilla Reisler Cavalcanti, et al...

associações de palavras como 'human', 'infection', 'transmission", 'reached', 'hands', 'vaccine'20. Já o cluster vermelha traz mais elementos geolocalizados, estando ligada a uma preocupação com determinadas regiões do planeta, como 'Japan, 'Thailand', 'Korea', 'chinese, 'illness', 'respiratory'21. O embate do grafo é entre as informações jornalísticas e as emoções despertadas pelas notícias da propagação do vírus.

O dia 21 de janeiro representa a ocasião em que a pandemia torna-se assunto do momento no Brasil, com tuítes em português, com destaque para as notícias da imprensa, como podemos notar na rede de palavras demonstrada na Figura 2, em que se destacam as associações de palavras como 'coronavírus', 'urgente', 'confirmado', 'pessoa', 'casos', 'vírus', 'mortes', 'surto'. Nesse dia, a conta do Ministério da Saúde publica a primeira menção do governo Bolsonaro sobre o surto da doença ${ }^{22}$. Indica que a administração era notificada do que vinha pela frente, ainda que a primeira postagem governamental tenha sido um desmentido de um boato que correlaciona o novo coronavírus a um outro que circulava no país, o ArenaVírus ${ }^{23}$.

Essa atuação da imprensa ${ }^{24}$ e dos órgãos multilaterais ${ }^{25}$ de saúde global (Organização das Nações Unidas ${ }^{26}$, OPAS ${ }^{27}$ ) de relatar o primeiro caso confirmado nos Estados Unidos e reportar sobre a multiplicação de casos e mortes na China confere compasso ao noticiário. Era a realidade se desvelando por meio de relatos sobre o avanço do vírus a países que se pensavam imunes às enérgicas movimentações no mundo globalizado. O contexto, em inglês e

\footnotetext{
20. Na ordem, humano, infecção, transmissão, alcançou, mãos, vacina.

21. Na ordem, Japão, Tailândia, Coreia, chinesa, doença, respiratória.

22. Cf. https://twitter.com/minsaude/status/1219701514366832642. Acesso em: 21 jan. 2020.

23. Cf. https://portal.fiocruz.br/noticia/especialista-esclarece-duvidas-sobre-o-arenavirus. Acesso em: 21 jan. 2020.

24. Cf. https://twitter.com/g1/status/1219699813429796864. Acesso em: 21 jan. 2020.

25. Cf. https://twitter.com/WHO/status/1219029418800226304?ref_src=twsrc\%5Etfw\%7Ctwcamp\%5Etweetembed\%7Ctwterm\%5E1219029418800226304\%7Ctwgr\%5E\&ref_url=https\%3A\%2F\%2Fwww.bbc.com\%2Fportuguese\%2Finternacional-51157487. Acesso em: 19 jan. 2020.

26. Cf. https://twitter.com/NacoesUnidas/status/1219486026223079425. Acesso em: 21 jan. 2020.

27. Cf. https://twitter.com/OPASOMSBrasil/status/1219307691065184256. Acesso em: 20 jan. 2020.
} 
Medo, infodemia e desinformação: a timeline dos discursos sobre coronavírus... Fábio Malini • Camilla Reisler Cavalcanti, et al...

português, mostra que, além de misteriosa, a narrativa sobre a pandemia incorporou relatos de urgência, amparada no sentimento de alerta, de emergência e vigilância ininterrupta. Sentimento este acentuado pela imprensa ocidental, que materializa o surto através da repetição de boletins com números de casos e de óbitos, mesmo que a doença ainda fosse referida ao desconhecido ${ }^{28}$.

É o jornalismo profissional quem dita o tom das conversas, ao tornar o cotidiano extraordinário empregando o "breaking news", afamado nas redes sociais em postagens com a exclamação URGENTE!, assim grafada, que opera como espasmos anunciativos. A consequência é uma comoção emocional on-line que, a curto prazo, cria um rebuliço que nutre a narrativa (mais comentários, mais alta intensidade emocional) e, a longo prazo, gera um panorama de instantaneísmo tautológico sobre a pandemia (uma repetição perseverante do mesmo discurso). A redundância quanto à urgência coabitava com a negligência. O não reconhecimento da seriedade do tema fez surgir uma aglutinação anedotal advinda da cultura do entretenimento. Nas redes fluem elementos de ironia, zombaria e descaso, estratégias de escape comuns de usuários ocidentais para lidarem com difíceis temas ou até negá-los.

$\mathrm{Na}$ análise de sentimentos, seguem o medo e a antecipação como predominantes nos dois idiomas, como mostram as Tabelas 3 e 4. Em inglês, estão presentes o medo (31,4\%), a antecipação $(19,64 \%)$, a confiança $(12,3 \%)$ e a raiva $(9,64 \%)$, como vemos na Tabela 3. Já em português, afloram outros sentimentos, como demonstra a Tabela 4. Liderados pelo medo (48,29\%), seguem-se a antecipação $(20,89 \%)$ em percentual bem acima do que o observado no dia 14 , além da raiva $(4,03 \%)$, da repulsa $(3,71 \%)$, da confiança $(2,95 \%)$ e da tristeza $(2,75 \%)$.

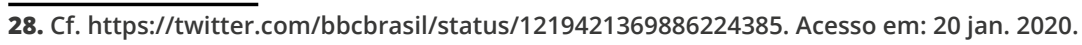


Medo, infodemia e desinformação: a timeline dos discursos sobre coronavírus... Fábio Malini • Camilla Reisler Cavalcanti, et al...

\section{Sentimentos Predominantes no dia 21 - Inglês}

40

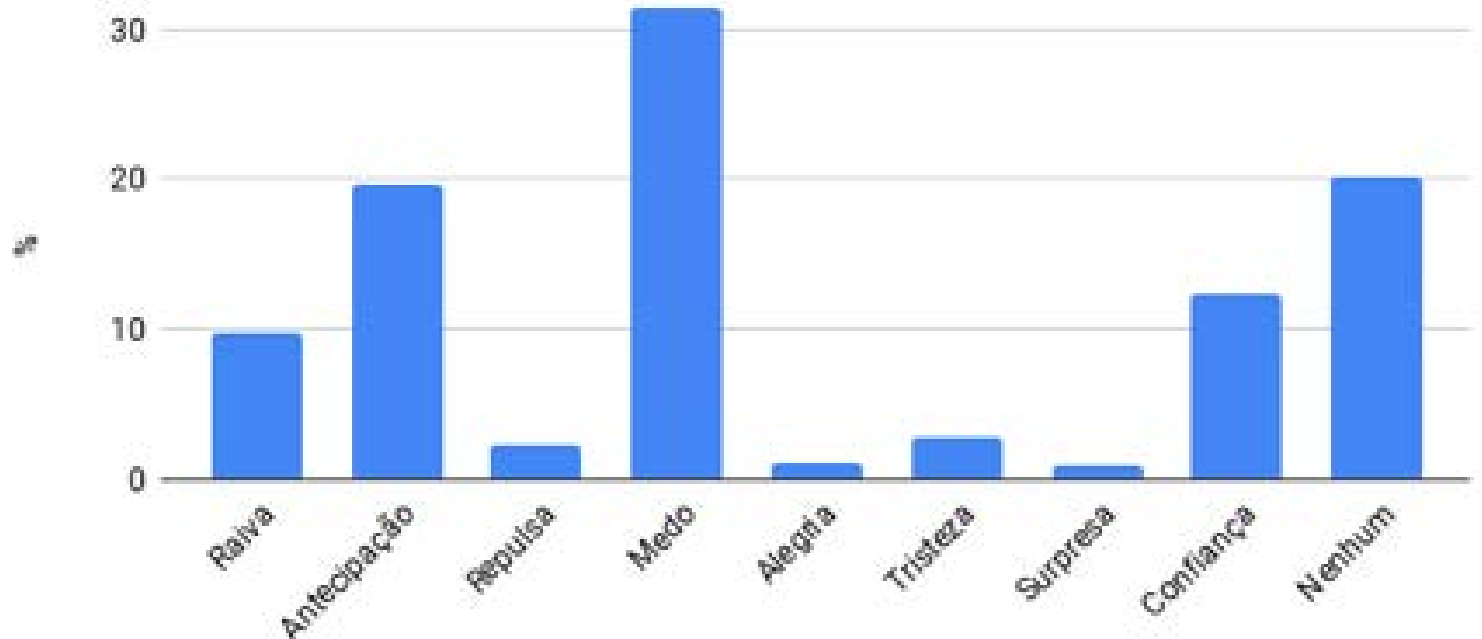

Tabela 3 - Análise de sentimentos preponderantes no Twitter, em português, no dia 21 de janeiro de 2020

20

Fonte: tabela produzida pelos autores, a partir de coleta de dados

\section{Sentimentos Predominantes no dia 21 - Português}

50

40

30

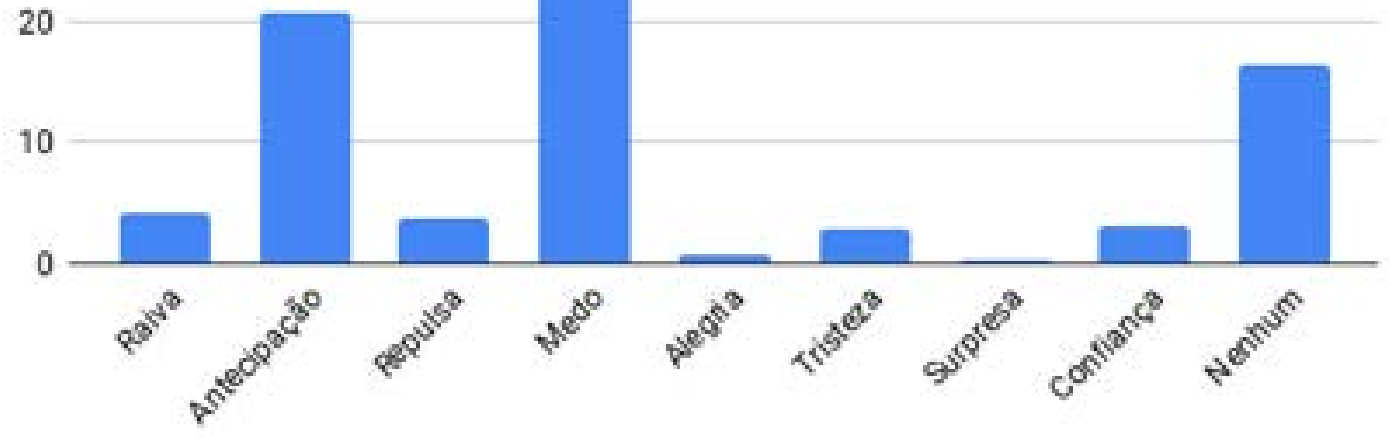

Tabela 4 - Análise de sentimentos preponderantes no Twitter, em português, no dia 21 de janeiro de 2020

Fonte: tabela produzida pelos autores, a partir de coleta de dados 
Medo, infodemia e desinformação: a timeline dos discursos sobre coronavírus... Fábio Malini • Camilla Reisler Cavalcanti, et al...

\section{A terceira narrativa: a emergência da desinformação}

A predominância dos sentimentos de medo, inquietação sobre o futuro (anticipation) e raiva caracteriza a maior parte dos os 630.400 tuítes em inglês e 111.365 em português, do dia 28 de janeiro de 2020, coincidindo com a emergência da desinformação no período. Em língua inglesa, representam mais de $70 \%$ do fluxo emocional de tuítes rotulados, sendo $26 \%$ de medo, $26 \%$ de antecipação e $19 \%$ de raiva, como mostra a Tabela 5. E mais de $80 \%$, em português, sendo $37 \%$ de antecipação, $23 \%$ de medo e $23 \%$ de raiva, como podemos visualizar na Tabela 6 .

Sentimentos Predominantes no dia 28 - Inglês

30

21
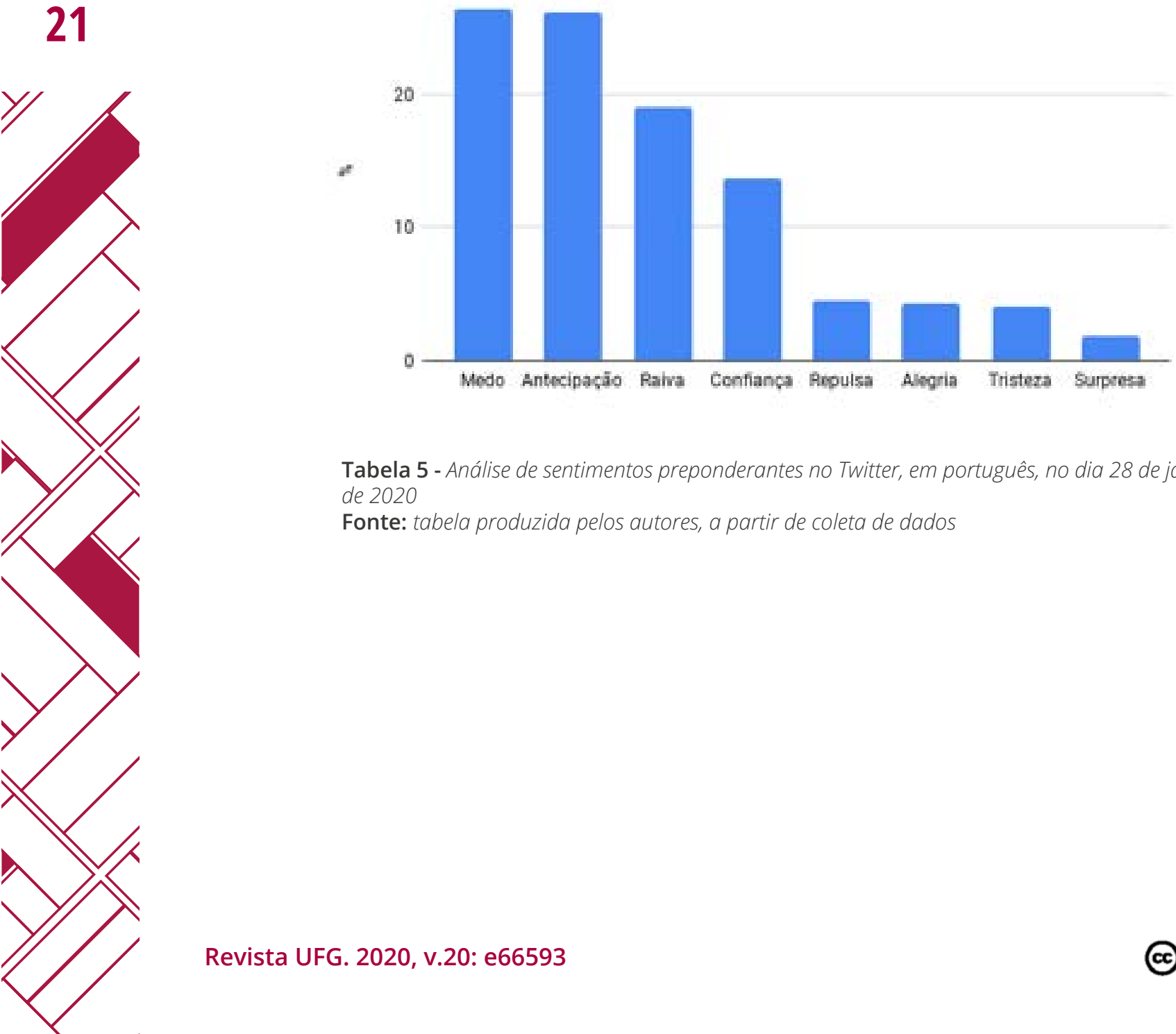

Tabela 5 - Análise de sentimentos preponderantes no Twitter, em português, no dia 28 de janeiro de 2020

Fonte: tabela produzida pelos autores, a partir de coleta de dados 
Medo, infodemia e desinformação: a timeline dos discursos sobre coronavírus... Fábio Malini • Camilla Reisler Cavalcanti, et al...

Sentimentos Predominantes no dia 28 - Português

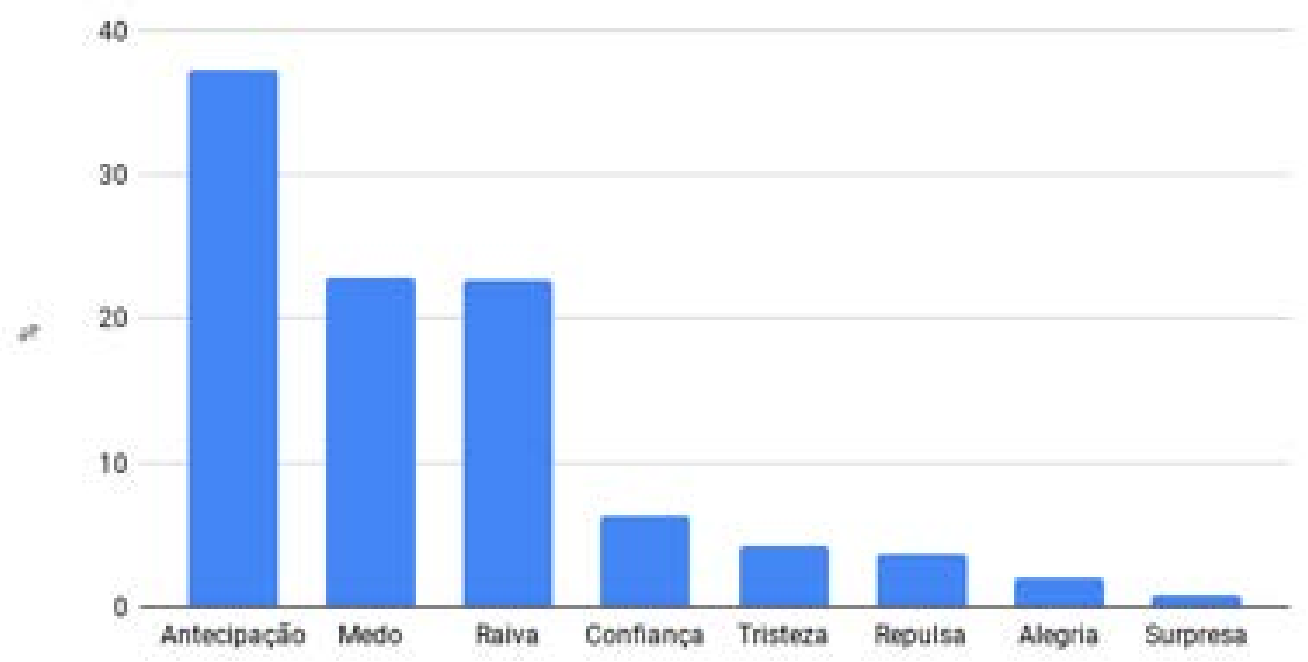

Tabela 6 - Análise de sentimentos preponderantes no Twitter, em português, no dia 28 de janeiro de 2020

Fonte: tabela produzida pelos autores, a partir de coleta de dados

22

Ao explorar as redes de termos na Figura 3, identificamos que há sentidos similares em inglês e português, considerando seus componentes mais conectados (amarelo e vermelho, respectivamente). No agrupamento amarelo, é possível visualizar que a força dos léxicos que conformam as narrativas de medo da disseminação da doença pelo mundo e dos primeiros casos suspeitos no Brasil, em Minas Gerais, daí a força de palavras como 'suspeita', 'suspeito', ‘paciente', 'sintomas', 'Alemanha', 'China', 'risco', 'medo', ‘urgente', ‘Índia', 'Japão', 'eua’. 
Medo, infodemia e desinformação: a timeline dos discursos sobre coronavírus... Fábio Malini • Camilla Reisler Cavalcanti, et al...
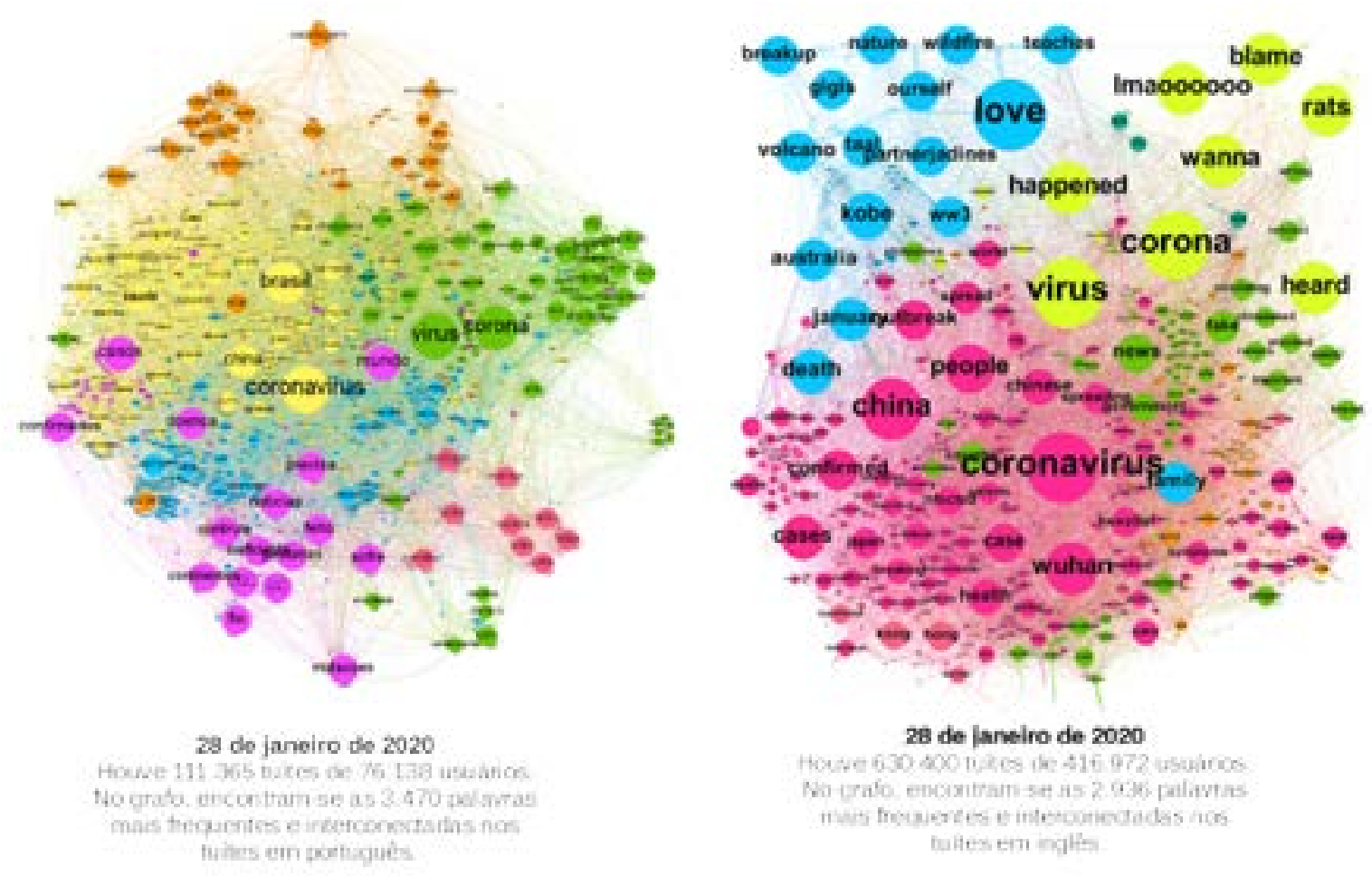

23

Figura 3 - Grafo de termos mais usados no Twitter, em português e inglês, em 28 de janeiro de 2020

Fonte: grafo produzido pelos autores, a partir de coleta de dados

Já no agrupamento vermelho, em inglês, esse universo vocabular é complementado com vocábulos como 'infected', 'hospital', 'medical care', 'toll', 'spreading', 'patients', 'outbreak', 'transmission', 'flu', 'deadly'29. Em ambos, portanto, o vocabulário da pandemia é marcado por uma linguajar epidemiológico, centrado na hospitalização e no contágio da doença, com intensa atenção a termos que denotam o risco e a letalidade concreta do vírus. Em português, adiciona-se a isso, por meio do agrupamento de palavras em verde, todo um vocabulário do sentimento de antecipação, com viés de preocupação e raiva, através de palavras como 'chegando' (para se referir que o vírus chegaria ao Brasil), 'porra', 'merda', 'vsf' (palavras chulas para designar ódio por vivenciar a situação), 'corona vírus' e 'morre' (como fatos indissociáveis da disseminação da doença).

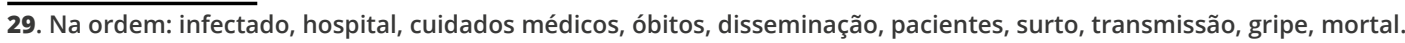


Medo, infodemia e desinformação: a timeline dos discursos sobre coronavírus... Fábio Malini • Camilla Reisler Cavalcanti, et al...

Um segundo elemento comum aos dois grafos é a presença da expressão "fake news". Em português, o termo é correlacionado com o presidente Bolsonaro, mas tem relação com uma mensagem viralizada que ironizava o fato de o presidente não saber lidar francamente com o assunto ${ }^{30}$.

$\mathrm{Na}$ nuvem de palavras mais intensamente conectadas em inglês, "fake news" sugere relação com 'rumours', "circulating", 'infection', 'cdc', 'wrong', 'Phillipines'. A conexão com a palavra rumor vinculava-se a uma sequência ${ }^{31}$ (thread) de post entre duas universitárias, em que uma delas, chinesa, explicava o que era verdade e mentira nas notícias publicadas sobre Wuhan no Ocidente, numa espécie de verificação de fatos em tempo real. A existência da co-associação entre fake-Phillipines denota um fato comum, em termos de desinformação no período: a disseminação de falsas alegações de confirmação de casos de coronavírus em diferentes países, como ocorria, no dia 28, sobre a Filipinas e Etiópia. O espírito da urgência e do medo estimulava a circulação de rumores sobre números da pandemia, especialmente aqueles que falsificavam informações sobre a quantidade de pacientes hospitalizados ou a criação de hospitais dedicados à doença na China ${ }^{32}$.

Esse estado contínuo de alerta e medo do desconhecido serviu de gatilho para que diferentes teorias de conspiração se espalhassem entre os dias 21 e 28 de janeiro, nos dois idiomas e contendo as mesmas histórias falsas. Em português, o epicentro da difusão da desinformação inicia-se com a circulação da teoria de que o coronavírus teria se alastrado devido aos hábitos alimentares exóticos dos chineses, em particular, a ingestão de sopa de morcego. A teoria é tratada como fato pela edição on-line do jornal

\footnotetext{
30. O tuíte, replicado 2.114 vezes, é de autoria de Lucas Rohan: “Diante da iminente confirmação do primeiro caso de \#coronavirus no Brasil, o governo Bolsonaro já deve estar buscando maneiras de acusar sabotagem e lançar aquele disparo amigo de fake news porque é assim que eles sabem lidar com crises".

31. Sobre isso ver: https://twitter.com/nolongerskek/status/1221827509030805504

32. "This "1,000 patient hospital" is FAKE! I know telephone, electrical engineering and hospitals. You can NOT wire and equip a bldg. to a hospital in only 2 days. So China's lying. But why? What for? What's the purpose for their fake Coronavirus reports? https://t.co/cCOzaGg3wi". Disponível em:
} 
Medo, infodemia e desinformação: a timeline dos discursos sobre coronavírus... Fábio Malini • Camilla Reisler Cavalcanti, et al...

Extra, por meio de um de seus blogs, o Page Not Found. Apesar de não checada, a "notícia" obteve 20 mil republicações na conta do Twitter do jornal. Essa era mais uma das histórias recicladas para confundir e desinformar a audiência on-line além de disseminar preconceito contra os chineses. Na verdade, o registro em vídeo da sopa tinha ocorrido em 2016, na Polinésia, por uma blogueira de viagens.

$\mathrm{Na}$ análise da rede do dia 28 em português, há ainda outra mentira distribuída por atores ligados ao bolsonarismo: o coronavírus estaria associado a experimentos com armas biológicas, segundo um blog da extrema direita norte-americana, o The Washington Times, e compartilhado ${ }^{33}$ pelo perfil no Twitter do site bolsonarista Crítica Nacional. Mas a principal teoria do dia foi levantada pelo blogueiro bolsonarista Leandro Ruschel, que comentava: "Aumentam as suspeitas sobre o vírus chinês ter escapado do laboratório de Wuhan"34. Tal teoria da conspiração era reforçada pelo youtuber bolsonarista Bernardo Kuster, que publicava: "Afinal, não estou tã̃ão louco assim. 'Wuhan, atingida por vírus, tem dois laboratórios vinculados ao programa chinês de guerra biológica'." ${ }^{35} \mathrm{~A}$ mensagem era seguida por um link ${ }^{36}$ de um post do Washington Times, cujo título dizia: "coronavírus pode ter sido originado em laboratório associado ao programa de guerra biológica chinês".

É no agrupamento azul da Figura 3 onde o vocabulário dessa desinformação é realçado, como as inter-relações lexicais 'guerra-biológica' e 'laboratório-chinês-tirania'. Curiosamente esses léxicos se entrelaçam no cluster com as palavras tais como 'Wuhan', 'cidade', 'ajuda', 'informações', 'vídeo' e 'comunista", que destacam vídeos sobre a quarentena forçada em Wuhan, pedidos de ajuda

\footnotetext{
33. https://twitter.com/criticanac/status/1222114145337860096

34. O tuíte foi excluído tempos depois pelo blogueiro. Mas consta registrado na base de dados, originalmente contendo o ID 1222171536238530561 no Twitter.

35. Cf. https://www.twitter.com/bernardopkuster/status/1222171536238530561. Acesso em: 28 jan. 2020.

36.. Cf. https://www.washingtontimes.com/news/2020/jan/26/coronavirus-link-to-china-biowarfare-program-possi/ Acesso em: 28 jan. 2020.
} 
Medo, infodemia e desinformação: a timeline dos discursos sobre coronavírus... Fábio Malini • Camilla Reisler Cavalcanti, et al...

humanitária, críticas a uma possível censura comunista e compartilhamentos de alertas sanitários na cidade chinesa. Alguns destes, de teor mais alarmista (formando o agrupamento lilás, com os termos 'casos', 'confirmados' e doença'), demonstram o alto grau de preocupação que o mundo deveria ter com o que ocorria na $\mathrm{China}^{37}$. Em inglês, repete-se esse imaginário negacionista de que o vírus teria sido criado em laboratório. Foi compartilhado 12 mil vezes no Twitter, associando a mentira à Fundação Bill e Melinda Gates. No delírio negacionista, o coronavírus seria patenteado pela Fundação com objetivos eugenistas. A mensagem, que circulou no dia 28, acabou sendo deletada da plataforma meses depois, ainda que as conversações em torno dela continuassem no ar. ${ }^{38}$

\section{6}

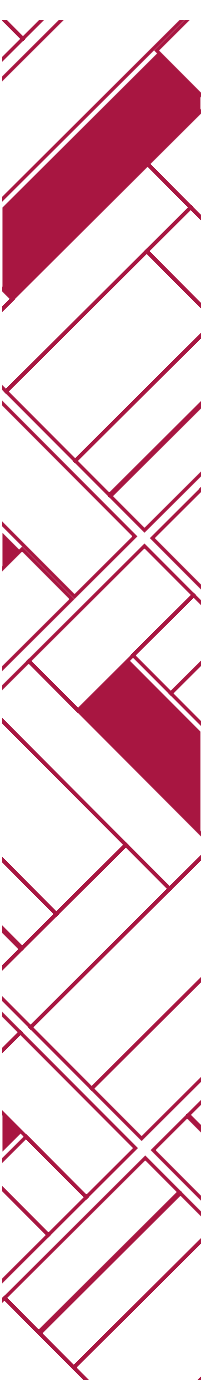

\section{Considerações finais}

Neste trabalho, apresentamos o que pensamos ser uma inovação na análise de redes sociais digitais, o conceito de timeline discursiva, sustentado em grafos baseado em palavras (que chamamos de redes de narrativas), como sendo uma instância para estudar temporalmente as mudanças da opinião pública, a partir dos léxicos que entram e saem da arena política das redes sociais. Foi por meio dessa metodologia que concluímos que as narrativas fixam expectativas e guiam a base emocional comum. Os sentimentos de medo e incerteza durante a pandemia pautam o comportamento de quem transita nas redes sociais. Essa pandemia reproduziu um padrão já presenciado pela humanidade, particu-

\footnotetext{
37. A mensagem foi a mais viralizada do dia, com mais de 35 mil republicações: "PÉSSIMAS notícias sobre o coronavirus O controle feito no mundo todo até agora foi ineficiente; O vírus sofre mutações; Quase todos os continentes tiveram casos confirmados; Tudo o que você precisa saber sobre a doença neste fio " https://www.twitter.com/celsolamounier/status/1222102070129561605 Acesso em: 28 jan. 2020.

38. O tuíte era: "The Bill \&amp; Melinda Gates Foundation predicted the Coronavirus could kill 65M people. And that was 3 months ago. The foundation also funded the institute that patented the virus. So a known eugenicist is funding lab-created diseases he thinks can kill millions of people? ". A conversação ainda está disponível na plataforma em: https://twitter.com/Education4Libs/status/1221845022582198277
} 
Medo, infodemia e desinformação: a timeline dos discursos sobre coronavírus... Fábio Malini • Camilla Reisler Cavalcanti, et al...

larmente, a incredulidade durante os primeiros contágios, a dúvida sobre os efeitos e o recolhimento forçado como fator de instabilidade nas relações sociais. $\mathrm{O}$ impacto mais negativo que pode-se obter em alimentar uma narrativa e hierarquizá-la acima das experiências humanas é o obscurecimento da dor física real e subjetiva, cenário proeminente no tempo da produção deste texto.

Quando os fatos se limitavam a um problema de saúde em Wuhan, a politização do surto questionava como as autoridades que administram a saúde global estavam lidando para descobrir as causas da misteriosa doença. Quando o surto se desloca em direção a um risco global de pandemia, é a própria China que se torna alvo das narrativas. O sentimento altruísta se esvai e entrarão em cena narrativas mais agressivas contra aquele país.

As redes de narrativas representam as formas como as palavras se entrelaçam para expressar um posicionamento político instanciado de um grupo on-line. Indicam rastros dos liames sociais entre atores em uma determinada rede. Representam teias de significações materializadas sobretudo por meio de palavras e imagens, observadas na forma de um grafo, dando visibilidade à forma-rede das narrativas com suas forças centrífugas e centrípetas. A atividade dos atores impulsiona a transformação ao longo do tempo, de maneira ainda mais abrupta quando aqueles estão em choque. O comportamento estrutural das narrativas, com seu desenvolvimento no tempo, forma uma timeline discursiva, que visualizada, no caso da pandemia, nos permite acompanhar os corpos das narrativas, dia a dia.

A incerteza não só foi fator fundamental de indagação frente ao controverso, compartilhado nas conversas que investem na ciência como atividade crucial para dominar o surto epidêmico, como também base para negá-la. A materialização diária da pan- 
Medo, infodemia e desinformação: a timeline dos discursos sobre coronavírus... Fábio Malini • Camilla Reisler Cavalcanti, et al...

demia por meio de números e gráficos (MAINGUENEAU, 202039), com as curvas e retas epidemiológicas mostra como nosso imaginário passou a lidar com a ingestão de um novo vocabulário. Termos como 'achatar a curva', 'distanciamento social', 'lockdown', 'isolamento', 'taxa de transmissão', 'quarentena' etc. fazem parte da nossa dieta lexical. Diferentes atores também são convocados para a interpretação e comunicação dessa ingestão. São estratégias que aliviam momentaneamente a angústia e o medo. Enquanto antes eram cientistas que diziam "a verdade" materializando o invisível, além de ter de possuir um discurso extremamente elaborado para sua preservação de face, agora são nada mais que uma peça de tabuleiro para legitimar as decisões políticas "urgentes". Isso porque abrir-se-ão também redes de narrativas desenhadas para confundir, para impregnar nossos pensamentos com a incerteza, já que várias dessas narrativas partirão de informações precárias em termos científicos principalmente no que toca ao tratamento e à cura. A timeline discursiva transforma-se em um cabo-de-guerra que, ao empurrar os léxicos para pólos opostos, emaranha-se em disputas sem fim.

\section{Referências}

BAUMAN, Zygmunt. Medo Líquido. Rio de Janeiro: Zahar, 2012. EdiçÃo DIGITAL, ARQUIVO EPUB.

CANCIAN, AlLan; MALINI, FÁbio. A nova Cara da direita no Brasil: um estudo sobre o grupo político MBL - Movimento Brasil Livre. IN: Anais do

10 Simpósio Direitas Brasileiras, Faculdade de Filosofia, Letras e Ciências Humanas da USP, 2017. Disponível EM: HTTP://CONFERENCIAS.FFLCH.USP.BR/ SDB/SIMPOSIODIREITAS/PAPER/VIEW/2199. ACESSO EM: 10 abr. 2019.

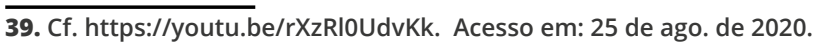


Medo, infodemia e desinformação: a timeline dos discursos sobre coronavírus... Fábio Malini • Camilla Reisler Cavalcanti, et al...

LEAL, Bruno. Saber das narrativas: narrar. In: GUimarãES, César; FRANÇA, Vera. Na mídia, na rua: narrativas do cotidiano. Belo HoriZONTE: AUTÊNTICA, 2006 P. 19-27.

MAINGUENEAU, D. QUEM FALA NA PANDEMIA: NOTAS SOBRE ETHOS E POR-TAvoz. Conferência live. LEEDIM-UFSCar. 27 de maio de 2020. Disponível: EM HTTPS://WWW.FACEBOOK.COM/LEEDIM.UFSCAR/VIDEOS/QUEM-FALA-NA-PANDEMIANOTAS-SOBRE-ETHOS-E-PORTA-VOZ/1028161050913072/. ACESSO EM: 25 оUт.2020.

MOHAMMAD, Salf M.; TURNEY, Peter D. Crowdsourcing A WordEmotion Association Lexicon. COMPUTATIONAINTELLIGENCE, v. 29, N. 3, Р. 436-465, 2013.

MURUNGI, D., PURAO, S., \& YATES, D. J. BEYOND FACTS: A NEW SPIN ON fake news in the age of social media. Paper presented at the Americas ConFERENCE ON INFormation Systems 2018: Digital Disruption, AMCIS 2018.

PLUTCHIK, Robert. A general psychoevolutionary theory of EMOtION. IN: Theories of emotion. AcAdemic PRESS, 1980. P. 3-33.

SeArgeant, Philip. The Art of Political Storytelling: why Stories WIN VOTES IN POST TRUTH POLITICS. London: Bloomsbury Academic, 2020. SONTAG, Susan. Doença como metÁFORA: AIdS e suAs metÁFORAS. SÃo Paulo: Companhia de Bolso, 1988.

WOLFF, Francis. Devemos temer a morte. In:NOVAES, Adauto. Ensaios sobre o medo. São Paulo: Editora Senac São Paulo; Edições Sesc São PauLO, 2007. P. 17-38. 